\title{
Понятие антиномии: терминологические границы и богословские аспекты
}

\author{
Горячев Д.А. \\ Московская духовная академия \\ 141300, Сергиев Посад, Троице-Сергиева лавра, Академия \\ E-mail: rasumihin@yandex.ru
}

\begin{abstract}
Аннотация. Приведено терминологическое разграничение понятия антиномии со смежными понятиями. Основное внимание уделено сопоставлению антиномии и парадокса как соответственно принципиально неразрешимому и принципиально разрешимому противоречиям. Рассмотрены примеры необоснованного расширения и ограничения предметной области антиномии. Определённость границ понятия антиномии достигается в исследовании через привлечение богословского материала, в основном из работ священника Павла Флоренского. Представления Флоренского об антиномии, претерпевшие изменения в развитии его философской и научной мысли и характеризующиеся логической завершённостью, положены в методологическую основу данного исследования. В работе подчёркнуто значение строгого антиномизма, исключающего паранаучные построения с использованием антиномии.
\end{abstract}

Ключевые слова: антиномия, парадокс, противоречие, совпадение противоположностей, Флоренский.

Для цитирования: Горячев Д.А. 2021. Понятие антиномии: терминологические границы и богословские аспекты. NOMOTHETIKA: Философия. Социология. Право, 46 (2): 230-238. DOI 10.52575/2712-746X-2021-46-2-230-238

\section{The concept of antinomy: terminological boundaries and theological aspects}

\author{
Daniil Goryachev, Priest \\ Moscow Theological Academy \\ Holy Trinity-St. Sergius Lavra, Sergiev Posad, 141300, Russian Federation \\ E-mail: rasumihin@yandex.ru
}

\begin{abstract}
Since Kant's critical philosophy, the concept of antinomy has been firmly established in philosophy. Currently, it is actively used in logic, cultural studies, theology, psychology, sociology, pedagogy, linguistics and other sciences. The article considers examples of unjustified expansion and limitation of the subject area of antinomy. A clear definition of the scope of this concept requires the establishment of its essential features. The essence of antinomy is revealed on the basis of the works priest Pavel Florensky, which give the most radical and at the same time logically complete answer about antinomy and its meaning. According to Florensky, truth is antinomy, Church dogma is necessarily antinomic, otherwise it becomes either a scientific position or a heresy. Antinomy involves maintaining a balance between its thesis and its antithesis. In this way, antinomy can be clearly distinguished from the related concepts of aporia, absurd, nonsense, paralogism, sophism and paradox. The main attention is paid to the comparison of antinomy and paradox as two contradictions, that differ on the basis of intentionality as, respectively, fundamentally unsolvable and fundamentally solvable by the methods of formal logic. The paper emphasizes the importance of strict antinomy, excluding parascientific construction with the antinomies.
\end{abstract}

Keywords: antinomy, paradox, contradiction, coincidence of opposites, Florensky. 
For citation: Goryachev D.A. 2021. The concept of antinomy: terminological boundaries and theological aspects. NOMOTHETIKA: Philosophy. Sociology. Law series, 46 (2): 230-238 (in Russian). DOI 10.52575/2712-746X-2021-46-2-230-238

\section{1. Введение: антиномии Канта}

Ответ на вопрос «что не является антиномией?» необходим для формирования строгой научной концепции антиномизма - установлению чётких границ понятия антиномии по принципу determinatio est negatio (определение есть отрицание). Приступая к негации, дадим предварительный ответ на вопрос «чем является антиномия?». На первый взгляд антиномия (с греческого $\alpha \dot{v} \tau \imath v \mu i ́ \alpha-$ противозаконие) представляет собой вполне сложившийся философский термин, начиная с «Критики чистого разума» (1781 г.) И. Канта, и определяется как противоречие между двумя одинаково обоснованными суждениями. Или еще более сжато: тождество противоречия $(\mathrm{A}=$ не-А).

Несмотря на то, что в понятие антиномии входит всего два компонента (противоречие и его синтез), каждый конкретный случай нуждается в обосновании - как логическом, так и мировоззренческом.

Даже кантовские антиномии чистого разума (Antinomie der reinen Vernunft) принимаются их автором только с рядом оговорок [Кант 2006, с. 327]:

1) о величине мира:

мир имеет начало во времени и границы в пространстве мир не имеет начала во времени и бесконечен в пространстве

2) о содержании мира:

всякая сложная субстанция состоит в мире нет ничего простого из простых частей

3) о порядке мира:

существует свобода все имеет свои причины

4) о Боге:

к миру принадлежит безусловно необходимое существо

нет никакого абсолютно необходимого существа

Сам Кант даёт логическое разрешение этим антиномиям, также и последующая критика (Гегеля, в первую очередь) показала неантиномичность указанных «антиномий». Вместе с тем за кантовским антиномизмом закрепилось определяющее значение: «Это мнимое разрешение мнимой антиномии, - В.С. Соловьев говорит об антиномии причинности и целесообразности, - заканчивающее последний из трех главных философских трудов Канта [“Критика способности суждения”], особенно ярко обнаруживает тот коренной недостаток всей его философии, который с необходимостью вызвал дальнейшее движение умозрительной мысли и делает безуспешным все попытки вернуть философию к чистому кантианству» [Соловьев, 1990, с. 470].

В тех же тонах пишет о значении кантовского антиномизма П.А. Флоренский: «В истории плоского и скучного мышления “новой философии” Кант имел дерзновение выговорить великое слово “антиномия”, нарушившее приличие мнимого единства. За это одно заслуживал бы он вечной славы. Нет нужды, если собственные его антиномии неудачны: дело 
- в переживании антиномичности» [Флоренский 2017, с. 164]. Критика кантовских антиномий представлена им в пробной лекции 1908 г. «Космологические антиномии Иммануила Канта» [Флоренский, 1996].

На наш взгляд, гораздо более глубоким ощущением и осознанием неразрешимости антиномического противоречия, по сравнению с Кантом, является учение Николая Кузанского о совпадении противоположностей (coincidentia oppositorum): «Надо вступить в область мрака, признать невмещаемое никаким рассудком совпадение противоположностей и искать истину там, где встает перед глазами невозможность. <..> Так я увидел, что место, где Ты обретаешься без покровов, опоясано совпадением противоположностей» [Кузанский, 1980, с. 53].

Однако необходимо обратить внимание на то, что отец Николай использует термин «противоположное» - различение понятий противоположного (opposita) и противоречивого (contraria) составляют основной вопрос строгого антиномизма. Противоречие есть вид противоположности, однако это такая противоположность, которая находится во взаимоисключении. Например, красное и белое противоположны, а противоречивы красное и не-красное. В связи с этим учение о совпадении противоположностей и антиномизм не тождественны.

\section{2. Антиномизм П.А. Флоренского}

Философский подход к определению антиномии как противоречию между двумя логически обоснованными положениями [Порус, 2010, с. 80] связан с формальными трудностями именно обоснования, которое может стать бесконечным спором. Отдельное преимущество в определении антиномии есть у теологии с её устойчивыми формами истинного. К примеру, текст Священного Писания более свободен от «спора о словах», так как имеет сложившуюся герменевтическую традицию. Формулы догматов также благодаря общепризнанности христианами могут служить иллюстрацией к антиномиям. В детально разработанном виде философско-богословское учение об антиномиях представлено у священника Павла Флоренского в книге «Столп и утверждение Истины» (примеры религиозных антиномий вынесены им в отдельную таблицу в конце Письма шестого «Противоречие»; комментарий к ним: [Горячев, 2019, 38-58]). Здесь антиномия формулируется как противоречие между двумя истинами [Флоренский, 2017, с. 169].

Примеры таких религиозных антиномий:

необходимость человеческого подвига (1 Кор. 9:24) — недействительность человеческого подвига (Рим. 9:16);

на суд пришел Я в мир (Ин. 9:39) - Я пришел не судить мир (Ин. 12:47);

всеобщее восстановление и блаженство (Рим. 8:19-23; 11:30-36) - двоякий конец (Рим. 2:5-12), погибель (2 Кор. 2-15). У Флоренского данная антиномия излагается следующим образом: «Тезис — “невозможна невозможность всеобщего спасения” — и антитезис — “возможна невозможность всеобщего спасения" - явно антиномичны. Но доколе признается Любовь Божия, - дотоле неизбежен тезис, а доколе признается свобода твари, сама составляющая необходимое следствие любви Божией, - дотоле неизбежен антитезис» [Флоренский, 2017, с. 214].

Сама истина, согласно Флоренскому, есть антиномия. Однако здесь речь не идёт о Истине-Боге (в Боге нет противоречия), а о той истине, которая является человеческой данностью. Так, церковный догмат - внутренне противоречив; сознательное принятие его требует веры. Если бы догмат был исключительно рационален, он перестал бы быть догматом веры, а стал бы научным положением. Также отказ от одновременного «да» и «нет» вероучительного положения, отказ от антиномии в пользу её тезиса или антитезиса приводит к ереси. Одновременное «да» и «нет» антиномии не есть лавирование или конъюнктура, а напротив - выдерживание между ними строгого равновесия [Флоренский, 2017, с. 148].

Первоначально Флоренским антиномия воспринималась в кантовском смысле как свойство разума. В работах, вышедших после «Столпа и утверждения Истины», антиномия 
приобретает характер бытийного принципа: антиномичны символ, культ, культура, слово, обряд и т.д. Антиномизм Флоренского можно трактовать как философское осмысление полярного мироустройства Его подход лежит в основе выяснения нами терминологических границ антиномии.

\section{3. Увеличение и уменьшение объема понятия антиномии}

Ошибка расширительного толкования антиномии (через включение в неё противоположного) приводит к её «тотальной» концепции, например: «...Антиномизм является одной из методологических установок диалектического метода, в основе которого лежит принцип противоположения сил, явлений, сущностей и этот принцип имеет очень древнюю родословную. Все первобытное, мифологическое мышление можно фиксировать как тотально антиномичное. В древней мифологии система противоположностей заполняет все сферы...» [Егорова, 2009, с. 15].

Не являются антиномиями такие диады, как душа и тело, духовное и плотское, идеальное и материальное. Сами по себе они не находятся в непримиримой вражде контрарности, примерами тому служат духовные вещи, сакральные предметы, святыни (икона, святая вода, храм) и овеществлённая духовность (откровение, видение потустороннего мира). Такой принцип аскетики «дай кровь и приими дух», казалось бы, предполагает, что именно плотское начало в человеке не позволяет развиться духовному. Однако здесь речь идёт об искажённой грехопадением плоти, и данный принцип уравновешивается другим: «мы не телоубийцы, а страстоубийцы» [Каллист, 2010, с. 342].

«Антиномия "Россия - Запад” в концепциях культурной самобытности» - сложно согласиться с таким пониманием антиномизма, т. к. Россия и Запад не исключают друг друга, не находятся в неразрешимом противоречии. Название другой диссертации: «Художественная репрезентация антиномии “добро/зло” в творчестве Н. Садур». Здесь опять речь идёт о противоположном. Более того, с точки зрения русской онтологической философии, зло не имеет собственного бытия и является искажённым добром: «То, что есть у Смерти — это лишь испоганенная ею же жизнь» [Флоренский, 2017, с. 173].

2. Другой ошибкой будет не видеть антиномического противоречия, принимая его только как противоположное (ошибка ограничения объема понятия). Полемизируя с П.А. Флоренским, Е.Н. Трубецкой не признаёт антиномию неслитного и нераздельного существования Божественной и человеческой природ во Христе, наделяя их статусом противоположных: «Антиномия была бы в том случае, если бы Церковь утверждала в одно и то же время и раздельность и нераздельность двух естеств и слиянность и неслиянность их; <...> нераздельность и неслиянность логически вовсе не исключают друг друга» [Трубецкой, 2001, с. 296]. С ним солидарен С.С. Хоружий [1999].

Понятия «нераздельность» и «неслитность» формально-логически не исключают друг друга. Но если выяснить смысл этих понятий, что конкретно они означают, какую предметную реальность они именуют и как они представляются человеческому сознанию, то противоречие становится очевидным. едино.

Что значит раздельно? Построим смысловой ряд: порознь, отдельно, не вместе, не

Что значит слитно? Также построим смысловой ряд: сплоченно, совокупно, цело, вместе, едино. Данный смысловой ряд наглядно демонстрирует, что он противоположен, а местами прямо противоречит первому ряду. Невозможно представить одновременную раздельность и нераздельность.

Что касается полемики Трубецкого с Флоренским, то это не выяснение вопросов логики, а выяснение вопросов мировоззрения [Трубецкой, 1989]. Так, именно антиномизм разграничивает философию П.А. Флоренского с философией всеединства В.С. Соловьева и Е.Н. Трубецкого: «Употребив в тексте определение Соловьева [истины как всеединого сущего], должны 
оговориться, что берем его лишь формально, вовсе не вкладывая в него Соловьевского истолкования; доказательство тому - все наше сочинение, состоящее по духу антиномичности против примирительной философии Вл. Соловьева» [Флоренский, 2017, с. 605].

3. В двух предыдущих пунктах разбирался такой компонент антиномии, как противоречие. Теперь рассмотрим вторую её составляющую, а именно синтетическую.

Не являются антиномией истина и ложь по причине отсутствия синтеза между ними. С этой точки зрения также можно рассмотреть добро и зло, не составляющие единства, но, например, не для нравственного релятивизма.

По своему тяготению к выяснению истины, а не антиномичному равновесию между двумя истинами, от антиномии отличаются абсурд, апория и парадокс.

Абсурд есть бессмыслица там, где должен был быть смысл (там, где смысл и не ожидался, присутствует нонсенс [Шкурская 2011, 15]). Абсурд есть противоречие смысла и бессмыслицы.

Апория есть противоречие между истиной и наличным опытом.

Антиномия и софизм различны как истина в виде ошибки и ошибка под видом истины.

\section{4. Антиномия и парадокс}

Чаще всего антиномия отождествляется с парадоксом. «Парадокс - мнение стран-

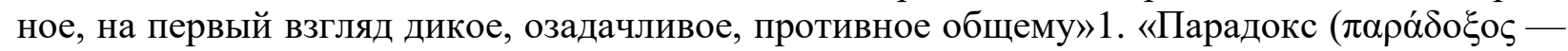
неожиданный, странный) - это высказывание либо рассуждение, которое доказывает как истинность, так и ложность некоторого предложения (или как его утверждение, так и его отрицание), выраженное формально-логическими средствами (посылками), кажущимися заведомо приемлемыми (логически правильными), но приводящими к заведомо неприемлемому результату (противоречию)»2.

Нами не выявлены какие-либо исследования по разграничению антиномии и парадокса. Потребность же в таком разграничении обусловлена следующим. Особенность антиномического противоречия заключается в том, что его составляют две истины, более того, сама истина, по Флоренскому, определяется антиномией. В итоге антиномия есть логически неразрешимое противоречие, находящая своё рассудочное примирение лишь в рамках опыта.

Напротив, парадокс стремится быть разрешённым, выясненным именно с помощью логики. Парадокс только внешне напоминает антиномию своей схемой «и А, и не-А», своим же существенным содержанием он говорит о выборе не между двумя истинами, а между истиной и ложью. Принципиальная неразрешимость антиномии и принципиальная разрешимость парадокса есть главное их отличие.

Отметим также психологическое содержание двух этих реальностей: парадокс в отличие от антиномии раздражает. Вполне возможно, что к этому заключению был близок отец Павел Флоренский, как раз писавший о раздражающем парадоксе [Флоренский 1991, c.11], хотя в его работах не проводится данное терминологическое обособление: «Движение мы разлагаем на ряд состояний покоя (кинематограф), непрерывное - на множественность элементов уже неделимых. На этом основаны вечно-истинные парадоксы [курсив авт. Г.Д.] Зенона: о летящей стреле и др.» [Флоренский, 1996, с. 31].

Рассмотрим примеры.

$\alpha$. Парадокс Эвбулида «Лжец» выглядит следующим образом: «Данное высказывание (А) есть ложь (В)». Рассмотрим два варианта выяснения истины:

если данное высказывание (А) действительно ложно (А есть В), то мы принимаем его как истинное высказывание (C); т. е. лжец в данном случае говорит правду (А не есть С), а данное высказывание в целом есть истина: (А есть В) есть С;

\footnotetext{
${ }^{1}$ Даль В.И. 1980. Толковый словарь живого великорусского языка. Т. 3. М., Русский язык, $555 \mathrm{c}$.

${ }^{2}$ Воробьева С.В., Непейвода Н.Н., Бернштейн В.С. Парадокс. 2002-2020 Гуманитарная энциклопедия: концепты / Центр гуманитарных технологий, //gtmarket.ru/concepts/6956
} 
если мы относимся к лжецу как лжецу, утверждающему, что А есть В, и он нас действительно обманывает, и А на самом деле есть $\mathrm{C}$, а не В, то выражение в целом не есть истина: (А есть В) не есть С.

В итоге мы принимаем или первый (не лжец), или второй вариант (лжец). «Либо то, либо другое» не подходит к определению антиномии, которая есть синтез противоречий: «и то, и другое».

Решение данного парадокса предлагает Л.Г. Антипенко с помощью логики Н.А. Васильева [Антипенко 2012]. Леонид Григорьевич приходит к выводу, что Лжец на самом деле утверждает ложь (в нашей схеме это второй вариант). Таким образом, и в данном случае парадокс лжеца не является антиномией вследствие разрешения противоречия.

$\beta$. Другим примером может послужить «парадокс Протагора», в котором тезис и антитезис выглядят антиномической парой.

У Протагора учился софистике Эватл. По заключенному между ними договору Эватл должен был заплатить за обучение только тогда, когда он выиграет свой первый судебный процесс. Однако, окончив обучение, Эватл не стал участвовать в судебных тяжбах. Как следствие, он считал себя свободным от уплаты за учебу. Протагор сам подал на своего ученика в суд. Таким образом, должен был состояться первый судебный процесс Эватла. Протагор привёл следующую аргументацию: «Каким бы ни было решение суда, Эватл должен будет заплатить. Он либо выиграет свой первый процесс, либо проиграет. Если выиграет, то заплатит по договору, если проиграет, заплатит по решению суда». Эватл возражал: «Ни в том, ни в другом случае я не должен платить. Если я выиграю, то я не должен платить по решению суда, если проиграю, то - по договору.

Из этого парадокса очевидно, что одновременно они не могут быть истиной и требуют выбора. Решение данного парадокса предложено Г. Лейбницем, согласно которому суд должен отказать Протагору, так как Эватл ещё не выиграл ни одного дела на тот момент. Но Протагор может потребовать уплаты денег после суда, так как Эватл уже выиграл своё первое дело. При этом первое решение суда не будет препятствовать Протагору получить деньги, так как ситуация после первого решения изменилась.

$\gamma$. Не антиномией, а парадоксом является вопрос «может ли Бог создать такой камень, который Сам не может сдвинуть?». Предлагается ответ: «Да, Бог всё может, и этот камень — человек».

Итак, парадокс стремится к своему разрешению (либо в ту, либо в другую сторону) - интуитивная и паранепротиворечивая логики подсказывают истинность одной из сторон парадокса. Антиномия, напротив, устанавливает баланс между тезисом и антитезисом.

Отметим, что провести разницу между антиномией и парадоксом важно и для богословия. Так, А. И. Сидоров характеризует парадокс Аполлинария Лаодикийского, который «горячо полемизируя против арианства... в христологии пришел практически к тем же выводам, что и ариане» [Сидоров, 2011, с. 152]. Вряд ли здесь может появиться соблазн назвать позицию Аполлинария антиномичной, но всё же отметим ясность терминологии: здесь справедливо употребленное понятие «парадокс» не означает интеллектуальной неразрешимости или трудности, а, скорее, неожиданный оборот дела, казусность ситуации, когда преследовалась цель одна, а результат получился другой. Важна здесь духовная оценка: «И опять можно наблюдать характерную черту аполлинарианства, как и многих других ересей: логические апории здесь явно преобладают над глубинным веросознанием Церкви, в данном случае церковном убеждением в полноте человечества Христа» [Сидоров, 2011, с. 152].

\section{5. Выводы}

Таким образом, мы обозначили ответ на вопрос «чем не является антиномия?». Она не является ошибкой (паралогизмом), софизмом, абсурдом, носенсом, апорией и парадоксом. Апофатическим путём мы подошли к исходному вопросу: «что ей не является?», т. е. 
какая реальность стоит за перечисленными понятиями, что именно отделяет от них антиномию? Мы также это выяснили - это сфера ложного, не-истинного. Следовательно, можно предположить, что реальность, охватываемая антиномией, есть сфера истинного. Данный вывод подтверждает взгляд отца Павла Флоренского на истину как антиномию.

Но если истина есть антиномия, то получается, истина, которая традиционно определяется через непротиворечие, теперь есть противоречие? Положение «истина есть антиномия» применимо только в металогике. В традиционной же логике истина определяется через непротиворечие тремя основными законами логики. Металогика или сверхрассудочное знание относится к действительности опыта, в частности духовного опыта. В последнем и находят своё разрешение религиозные антиномии.

Для классической логики антиномия также представляет собой объективную реальность, здесь также справедлива формула «истина есть антиномия», но только как внутренняя структура единой, не расколотой надвое истины. В качестве примера приведем понятие «слово», которое одновременно и моё, и не моё. Флоренский так это объясняет: сами мы не придумываем слова, мы пользуемся общенародным языком, но, произнося слово, мы всегда вкладываем в него уже наш собственный смысл, который может быть даже противоположным общепринятому; от нас зависит, каким по силе, духовности, выразительности, действенности, эстетичности и т. д. будет слово [Флоренский, 2017, с. 226].

Таким образом, в опыте антиномия дана нам как цельность, в бытии она синтезирована, но для рассудка она открывается двойственностью и несовместимостью, т. е. противоречием. Сознательное её примирение, разрешение, синтез даются на сверхрассудочном уровне: «И дело идет здесь поэтому совсем не о беспомощном, бессильном колебании или шатании, а об основанном на твердом решении и самоочевидно ясном узрении - свободном витании в средине или в единстве двух познаний - о витании, которому как раз и открывается последняя истина. Более того: эта трансрациональная позиция - будучи, в отношении объединяемых ею противоречащих отвлеченных познаний, “витанием” между или над ними - сама по себе есть совершенно устойчивое, твердо опирающееся на саму почву реальности стояние» [Франк, 1990, с. 313]. Непринятие этого уровня, как и антиномизма, связано с догматизированным пониманием истины как непротиворечия. Однако подлинная область догматов, теология, как видим, способна расширить парадигму истинного. Так, реальное существование антиномии обосновывается богословской наукой, в частности, работами священника Павла Флоренского.

Что же даёт нам строгий антиномизм? Он препятствует созданию паранаучных концепций на основе стратегии «чистого пространства» (Lebensraum, wild West), о которой сообщает С.С. Хоружий: «...Ее ключевой прием - смешение кардинально различных дискурсов. Если смешать, слить дискурсы с полярно противоположными правилами, то итогом смешения будет дискурс-беспредел, в котором нет никаких правил строгости и корректности, и потому притязать на истинность могут, вообще говоря, любые произвольные утверждения» [Хоружий, 2018, с. 598]. Антиномизм, утверждающий одновременные «да» и «нет», оказывается здесь вполне привлекательным. Даже у П.А. Флоренского можно увидеть одну не выверенную формулировку по поводу понимания Софии, Премудрости Божией: «Единый и целостный объект религиозного восприятия - в области разсудка распадается на множество аспектов, на отдельные грани, на осколки святыни... Раньше это было показано на разсудочных антиномиях догмата; сейчас речь будет о таких осколках, которые не находятся в явной антиномии друг с другом, потому что представляют не противоположное друг другу, а просто разное» [Флоренский, 2017, с. 324].

Сложно согласиться с отцом Павлом, когда он говорит об антиномии как о синтезе разного (С.М. Половинкин указывает: «Раскрывая сложность и многогранность данного концепта, автор выделяет 26 антиномических смыслов, придаваемых Флоренским Софии в разные годы» [2013, с. 44]). Тем более, Флоренский не обосновывает, почему антиномия может быть не только взаимоисключением тезиса и антитезиса. Здесь вполне находит место строгая антиномия, где тезис: София есть Христос, Божия Сила и Божия Премудрость 
Кор. 1:24); антитезис: София есть Божие творение. В отношении тезиса Флоренский справедливо указывает: «Конечно, нет никакого сомнения, что у свв. отцов под словом София весьма нередко разумеется Слово Божие, Вторая Ипостась Пресвятой Троицы; то же должно сказать и о богослужебных молитвах и песнопениях. Доказывать это общеизвестное положение цитатами - значило бы ломиться в открытую дверь» [Флоренский, 2017, с. 374]. Что касается антитезиса, то София предстаёт здесь «отпечатком» Бога в Своём творении, «прекрасным моментом твари» [Флоренский, 2017, с. 324], идеальным творением. Другими словами, перед нами антиномия Творца и творения, имманентности и трансцендентности Бога по отношению к миру. Согласно протоиерею Сергию Булгакову, данная антиномия представляет собой основную антиномию религиозного сознания: «Бог есть нечто, с одной стороны, совершенно трансцендентное, иноприродное, внешнее миру и человеку, но, с другой, он открывается религиозному сознанию, его касается, внутрь его входит, становится его имманентным содержанием» [Булгаков, 2001, с. 154]. Им же указывается, что проблема антиномизма в мышлении наиболее радикально поставлена в книге «Столп и утверждение Истины» [Булгаков, 2001, с. 155]. Заметим, что на основании того, что София определяется через антиномию, нами делается вывод о софийности антиномии и её эсхатологической будущности как непротиворечивого (в смысле не тягостного для ума) противоречия того мира, когда волк будет жить вместе с ягненком (Ис. 11:6).

\section{Список литературы}

1. Антипенко Л.Г. 2012. Флоренский П.А. о логическом и символическом аспектах научнофилософского мышления. М., Канон+, РООИ Реабилитация, 172 с.

2. Булгаков С.Н. 2001. Свет Невечерний: созерцания и умозрения. М., АСТ, 672 с.

3. 5. Горячев Д., свящ. 2019. Священник Павел Флоренский об антиномиях. Вопросы богословия, 2: 38-58.

4. Егорова С.Б. 2009. Антиномизм и диалектика в учении П.А. Флоренского: дис. ... кандидата философских наук. 09.00.03. Сарат. гос. ун-т им. Н. Г. Чернышевского, 156 с.

5. Каллист и Игнатий Ксанфопулы 2010. Наставления безмолвствующим. Добротолюбие в 5 т. / Пер. с греч. свт. Феофана Затворника. Т. 5. М., Изд-во Сретенского монастыря, 560 с.

6. Кант И. 2006. Критика чистого разума. Пер. с нем. Н. Лосского, сверен и отредактирован Ц. Г. Арзаканяном и М. И. Иткиным; Примеч. Ц Г. Арзаканяна. М., Изд-во Эксмо, 736 с.

7. Кузанский Н. 1980. Сочинения в 2-х т. Т. 2: Перевод. Общ. ред. В.В. Соколова и 3.С. Тажуризиной. М., Мысль, 741 с.

8. Половинкин С. М. 2013. Антиномическое понимание Софии у священника Павла Флоренского. Софиология и неопатристический синтез: богословские итоги философского развития. Сост.: К. М. Антонов, Н. А. Ваганова. М., ПСТГУ: 44-56.

9. Порус В.Н. 2010. Антиномия. В кн.: Новая философская энциклопедия: в 4 т. Т. 1. Ин-т философии Российской акад. наук, Национальный общественно-научный фонд ; науч.-ред. совет.: В. С. Степин - пред. совета и др. М., Мысль, 744 с.

10. Сидоров А.И. 2011. Святоотеческое наследие и церковные древности. Том 1: Святые отцы в истории Православной Церкви. М., Сибирская Благозвонница, 432 с.

11. Соловьев В. С. 1990. Сочинения в 2 т. 2-е изд. Т. 2. Общ. ред. и сост. А.В. Гулыги, А.Ф. Лосева. М., Мысль, 822 с.

12. 15.Трубецкой Е.Н. 2001 Свет Фаворский и преображение ума. П.А. Флоренский: pro et contra. Сост., вступ. ст., примеч. и библиогр. К. Г. Исупова. СПб, РХГИ: 283-313.

13. Трубецкой Е.Н., Флоренский П.А. 1989. Переписка князя Евгения Николаевича Трубецкого и священника Павла Флоренского. Вопросы философии, 12: 99-129.

14. Флоренский П., свящ. 1996. Сочинения в 4 т. Т. 2. Сост. и общ. ред. игумена Андроника (А. С. Трубачёва), П. В. Флоренского, М. С. Трубачёвой. М., Мысль, 877 с.

15. Флоренский П., свящ. 2017. Столп и утверждение Истины. Опыт православной теодицеи в двенадцати письмах. М., Академический проект, 905 с.

16. Флоренский П., свящ. 2017. У водоразделов мысли (Черты конкретной метафизики). Т. 1. М., Академический проект, 684 с.

17. Флоренский П. А. 1991. Мнимости в геометрии. М., Лазурь, 96 с. 
18. Франк С. Л. 1990. Сочинения. М., Правда, 608 с.

19. Хоружий С. С. 1999. Миросозерцание Флоренского. Томск, Водолей, 159 с.

20. Хоружий С. С. 2018. Опыты из русской духовной традиции. М., Институт св. Фомы, 648 с.

21. Шкурская Е.А. 2011. Лингвистическое сопоставление нонсенса и абсурда. Известия ВГПУ, 7 (61): 15-18.

\section{References}

1. Antipenko L.G. 2012. Florenskij P.A. o logicheskom i simvolicheskom aspektah nauchnofilosofskogo myshlenija [Florensky P. A. on logical and symbolic aspects of scientific and philosophical thinking: scientific monograph]. M., Publ. Kanon+, ROOI Reabilitatia, 172 p.

2. Bulgakov S.N. 2001. Svet Nevechernij: sozercanija i umozrenija [Light of the Evening: contemplations and speculations]. M., Publ. AST, 672 p. $38-58$.

3. 5. Goryachev D., priest. 2019. Priest Pavel Florensky on Antinomies. Theological Questions, 2:

4. Egorova S.B. 2009. Antinomizm i dialektika v uchenii P. A. Florenskogo [Antinomism and dialectics in the teaching of P. A. Florensky]: dis. ... kandidata filosofskih nauk : 09.00 .03 [Mesto zashhity: Sarat. gos. un-t im. N. G. Chernyshevskogo], 156 p.

5. Kallist i Ignatij Ksanfopuly 2010. Nastavlenija bezmolvstvujushhim [Instructions to the silent]. V. 5. M., Publ. Sretenskogo monastyrja, 560 p.

6. Kant I. 2006. Kritika chistogo razuma [Critique of pure reason]/ M., Izd-vo Jeksmo, 736 p.

7. Kuzanskij N. 1980. Sochinenija [Works]. V. 2. M., Publ. Mysl', 741 p.

8. Polovinkin S.M. 2013. Antinomicheskoe ponimanie Sofii u svjashhennika Pavla Florenskogo [Antinomic understanding of Sofia in the priest Pavel Florensky]. Sofiologija i neopatristicheskij sintez: bogoslovskie itogi filosofskogo razvitija. K.M. Antonov, N.A. Vaganova. M., Publ. PSTGU: 44-56.

9. Porus V.N. 2010. Antinomy. Novaja filosofskaja jenciklopedija. Vol. 1. M., Publ. Mysl', 744 p.

10. Sidorov A.I. 2011. Svjatootecheskoe nasledie i cerkovnye drevnosti [the Patristic heritage of the Church and of antiquity]. Tom 1: Svjatye otcy v istorii Pravoslavnoj Cerkvi. M., Publ. Sibirskaja Blagozvonnica, $432 \mathrm{p}$.

11. Solov'ev V. S. 1990. Sochinenija [Works]. Vol. 2. M., Publ. Mysl', 822 p.

12. 15.Trubeckoj E.N. 2001 Svet Favorskij i preobrazhenie uma [The light of Tabor and the Transfiguration of the mind]. P.A. Florenskij: pro et contra. SPb, Publ. RHGI: 283-313.

13. Trubeckoj E.N., Florenskij P.A. 1989. Perepiska knjazja Evgenija Nikolaevicha Trubeckogo i svjashhennika Pavla Florenskogo [Correspondence of Prince Eugene Nikolaevich Trubetskoy and priest Pavel Florensky]. Voprosy filosofii, 12: 99-129.

14. Florenskij P., svjashh. 1996. Sochinenija [Works]. Vol. 2 / Sost. i obshh. red. igumena Andronika (A. S. Trubachjova), P. V. Florenskogo, M. S. Trubachjovoj. M., Publ. Mysl', 877 p.

15. Florenskij P., svjashh. 2017. Stolp i utverzhdenie Istiny. Opyt pravoslavnoj teodicei v dvenadcati pis'mah [The pillar and statement of Truth. Experience of Orthodox theodicy in twelve letters]. M., Publ. Akademicheskij proekt, 905 p.

16. Florenskij P., svjashh. U vodorazdelov mysli (Cherty konkretnoj metafiziki) [At the watersheds of thought (Features of concrete metaphysics)]. Vol. 1. M., Akademicheskij proekt, 684 p.

17. Florenskij P. A. 1991. Mnimosti v geometrii [Imaginary values in geometry]. M., Publ. Lazur', 96 p.

18. Frank S. L. 1990. Sochinenija [Works]. M., Publ. Pravda, 608 p. Vodolej, 159 p.

19. Horuzhij S.S. 1999. Mirosozercanie Florenskogo [Philosophy Florensky]. Tomsk, Publ.

20. Horuzhij S.S. 2018. Opyty iz russkoj duhovnoj tradicii [Experiments of the Russian spiritual tradition]. M., Publ. Institut sv. Fomy, 648 p.

21. Shkurskaja E.A. 2011. Linguistic comparison of nonsense and absurdity. Izvestija VGPU, 7 (61): 15-18.

\section{ИНФОРМАЦИЯ ОБ АВТОРЕ}

Даниил Горячев, аспирант Московской духовной академии, Сергиев Посад, Россия

\section{INFORMATION ABOUT THE AUTHOR}

Daniil Goryachev, PhD student at the Moscow Theological Academy, Sergiev Posad, Russia 